\title{
Synthetic Polymeric Materials for Bone Replacement
}

\author{
Mônica Rufino Senra and Maria de Fátima Vieira Marques *ib \\ Technology Center, Bloco J, Instituto de Macromoleculas Professora Eloisa Mano, Universidade Federal do Rio \\ de Janeiro, IMA-UFRJ, Av. Horacio Macedo, 2030, Rio de Janeiro RJ 21941-598, Brazil; monicasenra@ima.ufrj.br \\ * Correspondence: fmarques@ima.ufrj.br
}

Received: 17 November 2020; Accepted: 18 December 2020; Published: 19 December 2020

check for updates

\begin{abstract}
Some treatment options available to repair bone defects are the use of autogenous and allogeneic bone grafts. The drawback of the first one is the donor site's limitation and the need for a second operation on the same patient. In the allograft method, the problems are associated with transmitted diseases and high susceptibility to rejection. As an alternative to biological grafts, polymers can be used in bone repair. Some polymers used in the orthopedic field are poly(methyl methacrylate), poly(ether-ether-ketone), and ultra-high molecular weight polyethylene (UHMWPE). UHMWPE has drawn much attention since it combines low friction coefficient and high wear and impact resistance. However, UHMWPE is a bioinert material, which means that it does not interact with the bone tissue. UHMWPE composites and nanocomposites with hydroxyapatite (HA) are widely studied in the literature to mitigate these issues. HA is the main component of the inorganic phase in the natural bone, and the addition of this bioactive filler to the polymeric matrix aims to mimic bone composition. This brief review discusses some polymers used in orthopedic applications, focusing on the UHMWPE/HA composites as a potential bone substitute.
\end{abstract}

Keywords: poly(methyl methacrylate); poly(ether-ether-ketone); ultra-high molecular weight polyethylene; hydroxyapatite; orthopedic applications

\section{Introduction}

Most bone tissue lesions have the potential for adequate spontaneous regeneration, and this is mainly due to the continuous bone remodeling process that occurs throughout human life [1]. However, in pathological fractures or large bone defects, bone healing and repair fail, and bone substitutes are needed [2]. The most common substitutes include autogenous and allogeneic bone grafts [3]. The first one is biologically considered the gold standard for bone replacement. In this type of graft, the bone tissue is transplanted from one place to another in the same patient, providing immunocompatible living bone cells. However, removal of autogenous bone is costly, painful, and can result in injury, infection, and morbidity of the donor site [4-6].

On the other hand, the allogenous graft is obtained from another individual of the same species. Using this type of graft has the advantage that there is no longer the need to perform a second surgery on another part of the patient's body. It is also possible to biologically reconstitute a long bone deficit without the morbidity of the donor site. Nonetheless, this type of graft is more susceptible to rejection, and even being submitted to previous treatments can cause disease transmission [7-9].

The use of these biological grafts can damage the body, and their supply is limited [3], so the search for alternative materials is a constantly evolving field. One of the biggest challenges for developing materials that can be used as artificial bones is that they should be biologically and mechanically similar to natural bone tissue to prevent rejection of the body's implant. Alternatively, metals, ceramics, and polymers have been used to repair or rebuild bones [10]. 
An ideal bone substitute should have some important properties: it should be biocompatible with the host and not cause an adverse inflammatory response; it should be easily molded to a bone defect; the durability of the implant is important to maintain its form and volume over time, it should also be bioactive, capable of being sterilized and readily available at a reasonable cost [11].

Polymeric materials in bone replacement have the advantage that their physical characteristics can be molded according to their application since their composition can be easily changed. They can be produced in a more porous or smooth form; they are easily manipulated, allowing better reproduction and lighter ones than metals. However, they have inferior mechanical properties and lack adhesion to the living tissues [12].

A widely studied material for the manufacture of prostheses is ultra-high molecular weight polyethylene (UHMWPE). Mechanical properties similar to natural bone, high impact, wear resistance, low friction coefficient, and biocompatibility make it a suitable polymer for bone replacement $[13,14]$. For this reason, UHMWPE is widely used to fabricate hip, knee, and shoulder prostheses.

Nevertheless, UHMWPE is a bioinert material, and its fixation to the bone is only possible using poly (methyl methacrylate) (PMMA) as bone cement. PPMA provides an excellent primary mechanical fixation of the implant but does not provide cellular adhesion to the cement [15].

The combination of UHMWPE and a bioactive material would provide conditions for direct binding of this polymer to the bone, obtaining a biomaterial suitable for bone replacement, combining mechanical properties and bioactivity similar to those of bone. Attempts to make UHMWPE bioactive have been made, and one of them is the addition of hydroxyapatite (HA) to this polymeric matrix. HA is the main mineral constituent of bone, and its use aims to promote osseointegration (direct contact between living bone and implant, without the formation of fibrous tissue) [16].

In this short review, the bone composition is first discussed to understand better the tissue that will be replaced. Second, we revised the polymers usually used in bone repair, highlighting UHMWPE/HA composites' properties and their processing strategy.

\section{Bone Composition}

Bone is an organ that performs some human physiological functions, including organ protection, soft tissue support, locomotion, mineral storage (mainly calcium), and blood cell production [17]. Despite its rigid structure, bone is a living and dynamic element with the capacity for self-regeneration and self-remodeling [18]. Understanding the physiological structure of bone and its composition is essential to design biomaterials, implants, and devices.

Bone is a porous material consisting of water, a mineral phase whose main component is hydroxyapatite $\left(\mathrm{Ca}_{10}\left(\mathrm{PO}_{4}\right)_{6}(\mathrm{OH})_{2}\right)$, and an organic phase consisting of approximately $90 \%$ type I collagen, $5 \%$ non-collagen bone proteins, and $2 \%$ lipids [19]. The organic phase represents approximately $25 \%$ of the bone composition, while the inorganic phase represents $70 \%$ and water $5 \%$ [20]. The relative proportions of these components may vary according to some factors such as age, gender, and individual health status [21].

The bone must be rigid and able to resist deformation. However, it should also be flexible: it must be able to absorb energy when deformed, to shorten and lengthen when compressed, and to stretch and narrow when subjected to tension, without breaking down [22]. The organic phase provides a certain degree of flexibility and elasticity typical of bone. On the other hand, the inorganic phase is responsible for providing hardness and resistance to mechanical stress [23].

There are two main types of bone: cortical (about $80 \%$ of the total skeleton present in the body) and trabecular bone (the remaining $20 \%$ of the skeleton). Table 1 compares the composition of cortical bone and trabecular bone and their strength and elasticity. 
Table 1. Bone composition and mechanical properties. Reproduced with permission from [24].

\begin{tabular}{cccccc}
\hline \multirow{2}{*}{ Bone Type } & \multicolumn{2}{c}{ Composition (\% Mass) } & \multicolumn{2}{c}{ Mechanical Properties } \\
\cline { 2 - 6 } & Protein & CaP & Water & Strength (MPa) & Elastic Modulus (GPa) \\
\hline Cortical & 28 & 60 & 12 & $70-200$ & $3-30$ \\
\hline Trabecular & 26 & 54 & 20 & $0.1-30$ & $0.02-0.5$ \\
\hline
\end{tabular}

Although both bones have a similar composition, the cortical bone's strength is about $85 \%$ higher than that of the trabecular bone. It happens because the cortical bone is denser and more solid with 5-30\% porosity, compared to the trabecular bone, which has a porosity of 70-95\%. It indicates that the bone strength does not depend only on its composition but also on the bone's mass, geometry, and microstructure [24]. Bone architecture is organized in a complex hierarchical structure, ranging from macro to nanostructure [23]. At different scales, bone has different building blocks. These delicate arrangements allow the integration of excellent mechanical properties and multiple biological functions [21]. Figure 1 shows the hierarchical structures of the bone. From macro to the nanoscale, each level has particular units and arrangements that support and affect larger and smaller scales.

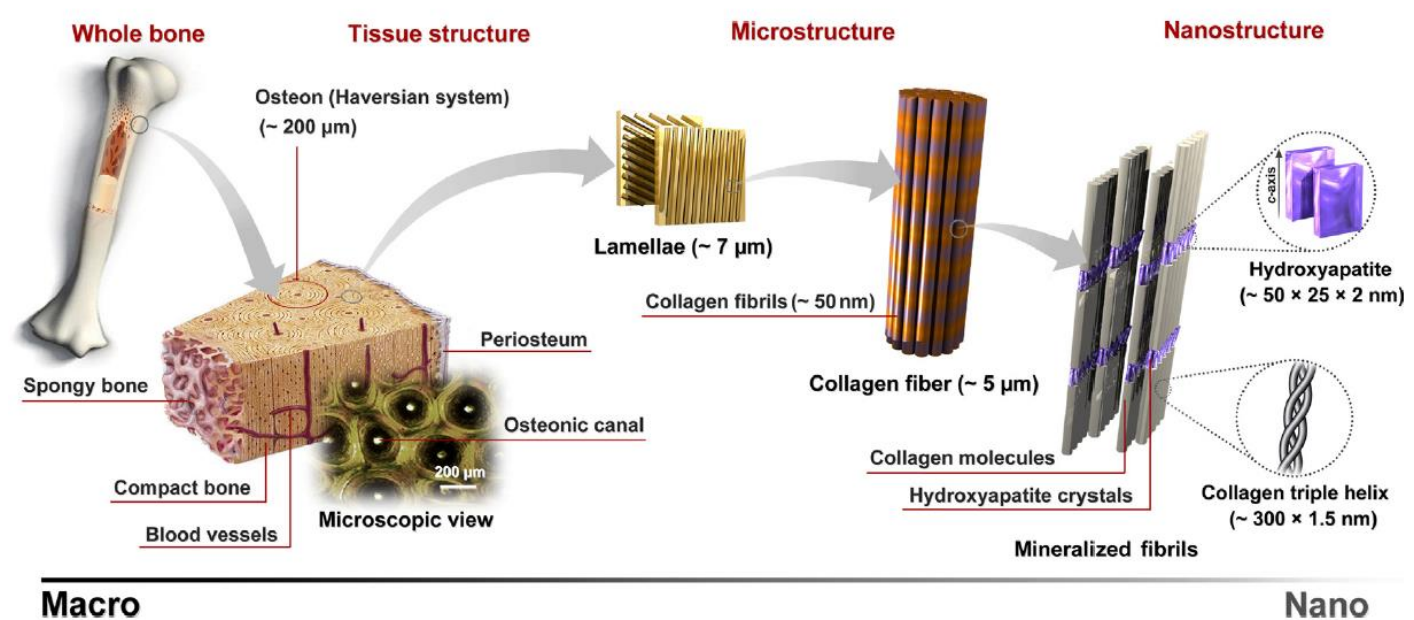

Figure 1. Hierarchical structural organization of the bone [25].

Cellular components are the essential factors for the activation and control of bone metabolism. Bone tissue is associated with different types of cells: osteoblasts, osteocytes, and osteoclasts. All of them have defined tasks and are essential for maintaining healthy bone tissue (Table 2).

Table 2. Bone cells and their functions. Reproduced with permission from [26].

\begin{tabular}{cc}
\hline Cell Type & Function \\
\hline Osteoblasts & $\begin{array}{c}\text { Synthesis and regulation of the deposition and mineralization of the } \\
\text { extracellular bone matrix; } \\
\text { Response to mechanical stimuli. }\end{array}$ \\
\hline Osteocyte & $\begin{array}{c}\text { Calcification of the osteoid matrix; } \\
\text { Bone maintenance; } \\
\text { Osteoclast }\end{array}$ \\
\hline
\end{tabular}

\section{Polymers in Orthopedic Applications}

The need to develop effective and reliable regeneration strategies is evident when it is observed that in the USA, 93,122 total hip replacements and 139,582 total knee replacements were performed in 
2018 [27], and it is estimated that by 2030 the annual value of a knee will be more than one million [28]. Implantable prostheses have a great potential to improve human health, improving the quality of life. These devices replace part or all of the damaged or sick organ with an artificial device [29].

When bone tissue damage is irreversible and cannot be regenerated, non-biodegradable polymers can be used to partially or totally replace the injured bone or joint. Non-biodegradable polymers such as poly(methyl methacrylate), poly(ether-ether-ketone), and ultra-high molar mass polyethylene are the most investigated for orthopedic applications [30].

\subsection{Poly(methyl methacrylate)}

Poly(methyl methacrylate) (PMMA) is a rigid thermoplastic polymer, biocompatible, biologically inert, and hydrophobic. It is easily obtained from the polymerization of methyl methacrylate through mass, emulsion, or solution polymerization process [30].

In 1960, Charnley introduced PMMA as bone cement in orthopedics in analogy to dental cement already used [30]. This cement is formed by a powder and liquid phase. The powder phase contains pre-polymerized PMMA, an initiator, a radiopacifier $\left(\mathrm{BaSO}_{4}\right.$ or $\mathrm{ZrO}_{2}$ - which turns the cement visible on the radiograph) and may also contain additives such as antibiotics. The liquid phase is formed by the MMA monomer, an accelerator, and a stabilizer. These two phases are mixed until a paste is formed, taking place the polymerization, and finally, the cement can be applied.

Bone cement provides excellent primary fixation between the bone and implant but does not provide cellular adhesion. The dense and non-porous structure of the material avoids bone growth in the cement layer, providing only mechanical fixation. In addition, PMMA bone cement has other disadvantages associated with its use: the residual monomer can enter the bloodstream and cause embolism; the temperature released during cement mixing can produce thermal necrosis in the bone or adjacent tissues; the shrinkage of cement during polymerization can produce free spaces and loss of contact between cement and prosthesis or between cement and bone; excess of tension can cause cement fractures and release of cement particles, which can be interacting with the surrounding tissues generating an inflammatory reaction [31].

Despite the disadvantages mentioned, PPMA bone cement is still clinically used with a success rate. They are generally used for orthopedic prostheses fixation, filling craniofacial defects, and repairing fractured vertebrae [11].

Bone cement is formed through a mass polymerization reaction of methyl methacrylate (MMA) via free radicals, where benzoyl peroxide is generally used as an initiator and $N, N$-dimethyl-4-toluidine as an activator (Figure 2). This reaction leads to the formation of free radicals of benzoate and amine, which can induce local inflammation. An alternative to reduce the number of free radicals formed is the addition of vitamin E. Incorporating this antioxidant to the solid phase of the cement in the proportion of 1:1.8 provides an increase in cytocompatibility and a decrease in exothermic activity, reducing the likelihood of bone necrosis. However, the setting time (time taken to form the cement) increases (20.7 min with vitamin E against $12.2 \mathrm{~min}$ without the antioxidant), which exposes the site that will be operated to the environment for a longer time, increasing the risk of infection. Studies have shown that the ideal amount of vitamin $\mathrm{E}$ to be added in PMMA is 10\% since this concentration positively affects free radical oxidation and exothermic activity and does not significantly affect the final material's mechanical resistance [32].

Another approach used to improve acrylic bone cement performance is to incorporate bioactive inorganic fillers into the PMMA matrix as hydroxyapatite, bioactive glasses, and akermanite (calcium magnesium silicate- $\mathrm{Ca}_{2} \mathrm{MgSi}_{2} \mathrm{O}_{7}$ ). Chen et al. [33] added akermanite (AKT) to PMMA and noted that AKT's incorporation significantly improved PMMA properties, including lower polymerization temperature, proper setting time, and high mechanical strength. PMMA/AKT bone cement also showed improvement in osteogenic activity, demonstrating that PMMA/AKT bone cement is a promising material in orthopedic applications. 


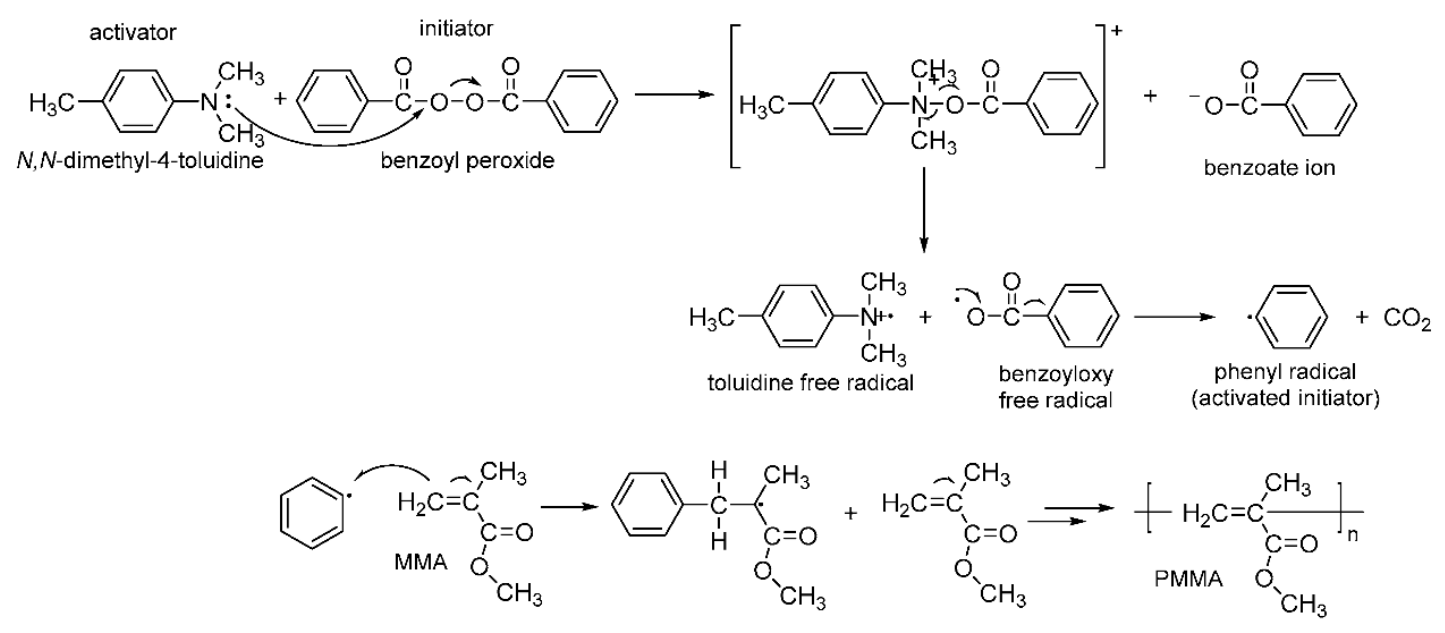

Figure 2. Schematic diagram showing methyl methacrylate (MMA) polymerization. Reproduced with permission from [34].

Hydroxyapatite (HA) is the main mineral constituent of bone and is often added to bone cement to promote osseointegration. Another strategy that can induce osseointegration is porosity, allowing bone growth in its pores. Sa et al. [35] investigated the mechanical properties and mineralization capacity of porous PMMA/HA composite. The results showed that the mechanical properties were deeply affected by the increase of porosity, while the addition of HA did not significantly affect the mechanical properties. On the other hand, a higher HA content enhanced the mineralization ability of cement. It was also found that the polymerization temperature was significantly reduced in the composites and the setting time was about $7 \mathrm{~min}$ for the cement.

Goñi et al. [36] studied composites of PMMA with a bioactive glass $\left(\mathrm{SiO}_{2}-\mathrm{CaO}-\mathrm{P}_{2} \mathrm{O}_{5}\right)$, where $0-20 \%$ of calcium was replaced by strontium ( $\mathrm{Sr}$ ). Sr ions produce beneficial osteoporosis treatment effects, reduce bone resorption, and stimulate bone formation by osteoblast. Sr also acts as a radiopaque agent (agent capable of absorbing radiation), allowing its observation on medical diagnostics images $[37,38]$. The study results showed that the addition of Sr-bioactive glass to PMMA promoted decreased reaction temperature, conferred better bioactivity, and the cement presented good radiopacity. It was also observed an increase in the composites' elastic modulus with the filler content, showing that Sr-Bioactive glass also acted as a reinforcement agent.

\subsection{Poly(ether-ether-ketone)}

Poly(ether-ether-ketone) (PEEK) is an aromatic, semicrystalline thermoplastic polymer, thermally stable at high temperatures. It is chemically inert and insoluble in most solvents at room temperature. It can be synthesized by two main routes: the first involves electrophilic reactions, and the second route involves nucleophilic displacement reactions (Figure 3) [39,40].

Although PEEK is biocompatible and chemically resistant, it is biologically inert, not providing a good interaction with the bone tissues surrounding the implant, which can trigger implant failure. Some studies have been developed to turn PEEK into a bioactive material and improve bone-implant interaction [41-49]. One approach is to modify PEEK's surface, and the other strategy is to prepare PEEK bioactive composites [50].

When a biomaterial is placed in a biological environment, the first molecules that reach the implant surface are the water ones. Then proteins interact with the biomaterial, and this contact is affected by the adsorbed water molecules. Subsequently, the adhesion of cells that interact with the adsorbed proteins occurs, influencing tissue growth [51,52]. The low surface energy of PEEK limits its cellular adhesion. Since the water molecules first interact with the device implanted, it is important to have a hydrophilic surface, i.e., a high surface energy substrate. It is well established that surfaces with higher energy are known to promote rapid cell adhesion and spreading, in contrast to surfaces with lower 
energy. Thus, by changing a polymer's surface energy, its surface reactions can be changed, creating an ideal surface for the desired application [53]. Wang et al. [54] modified PEEK's surface by plasma immersion ion implantation, grafting hydroxyl groups on its surface, providing a hydrophilic character to the modified material. The cytocompatibility of the pure polymer and the modified polymer was also evaluated. It was observed that the adhesion, spreading, and proliferation of osteoblasts are significantly improved on the modified surface, which can induce a faster bone maturation around the implant.

(a)

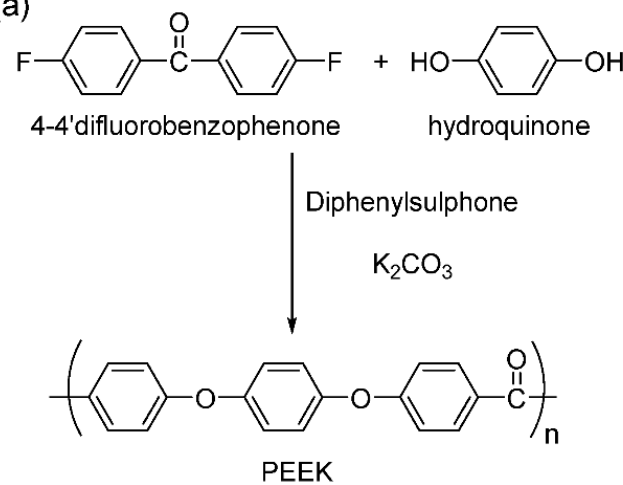

(b)

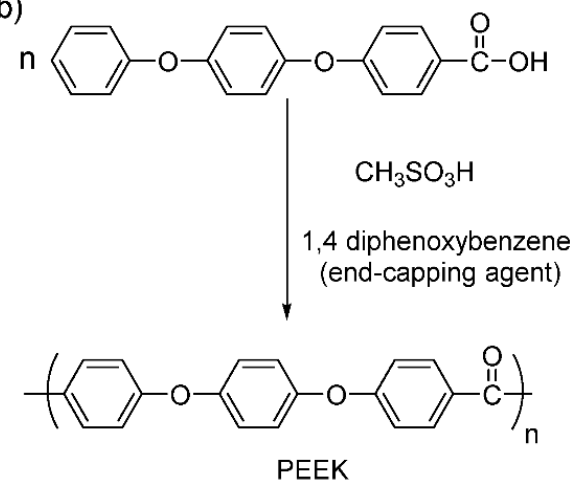

Figure 3. (a) Nucleophilic and (b) electrophilic poly(ether-ether-ketone) (PEEK) synthesis. Adapted from [39].

Some bioactive fillers introduced to PEEK to produce composites are beta-tricalcium phosphate, hydroxyapatite, and bioactive glasses. A widely studied composite is PEEK/HA due to HA biocompatibility, bioactivity, and osteoconductivity [50]. However, adding a high amount of HA to the polymeric matrix can reduce its strength while its bioactivity is improved [55]. Ma et al. [56] developed PEEK/nano-HA composites. An increase in the elastic modulus and the compressive strength for the composites were noticed, while the tensile strength decreased compared to pure PEEK. The biological assays showed that PEEK/nano-HA composites promoted adhesion, spreading, and cell proliferation, besides osteogenic activity.

\subsection{Ultra-High Molecular Weight Polyethylene in Orthopedic Applications}

Each year, about three million bone joint replacement procedures are performed worldwide, and most of these implants incorporate UHMWPE [57].

UHMWPE has an elastic modulus closer to the bone than other materials commonly used in prostheses such as Co-Cr-Mo and Ti-6Al-4V metal alloys (Table 3). Protheses with an elastic modulus very different from natural bone can generate the stress shielding phenomenon, which leads to a reduction in the normal mechanical load of the bone due to the bone-implant interaction, which may result in bone loss surrounding the implant.

Most commercial orthopedic implants approved by the Food and Drug Administration (FDA) have mechanical properties that deviate by one order of magnitude from the cortical bone, which is used as a reference to compare the mechanical properties of implants. The cortical bone forms the bone's external wall, while the trabecular bone is found inside. Thus, the cortical bone is the one that will be in contact with the implant directly. Figure 4 illustrates an Ashby diagram with data compiled by Roeder et al. [58] that shows the elastic modulus and fracture toughness of human bone compared to materials commonly used in orthopedic implants. It can be observed that the mechanical properties of the cortical bone and the UHMWPE are remarkably close in the diagram. 


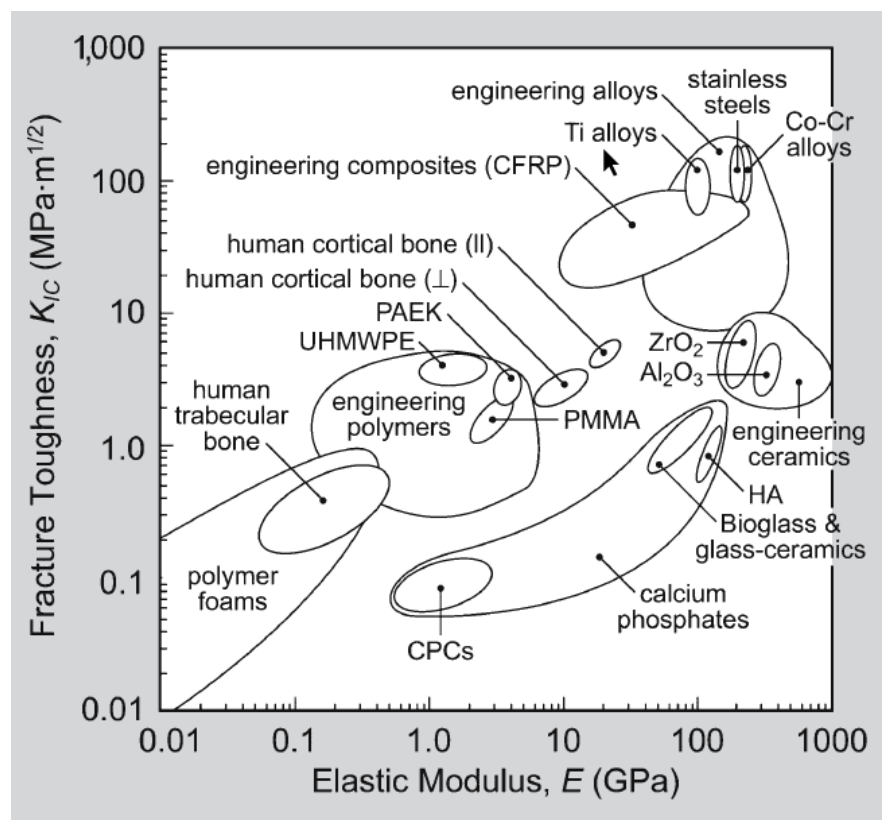

Figure 4. Ashby diagram correlating elastic modulus and fracture toughness of human bone and materials used in orthopedic implants. The mechanical properties of cortical bone are shown for parallel (II) and perpendicular $(\perp)$ load applied to the anatomic longitudinal axis. Reproduced with permission from [58].

Table 3. Elastic modulus of bone and materials commonly used in the manufacture of prostheses.

\begin{tabular}{ccc}
\hline Material & Elastic Modulus (GPa) & Tensile Strength (MPa) \\
\hline Trabecular bone & $0.02-0.05[24]$ & $1-5[59]$ \\
Cortical bone trabecular & $3-30[24]$ & $50-151[59]$ \\
UHMWPE & $0.9-2.7[60]$ & $33-66[61]$ \\
PMMA & $1.88-3.3[60]$ & $68[62]$ \\
PEEK & $3.5-4.0[63]$ & $118[62]$ \\
Co-Cr-Mo alloy & $210-232[60]$ & $1173[64]$ \\
Ti-6Al-4V alloy & $116[60]$ & $1018[65]$ \\
\hline
\end{tabular}

It is noteworthy that the biocompatibility of UHMWPE is only ensured if its macroscopic integrity is preserved. However, during joint movements, wear of the polymer surface occurs. Some residues of the polymeric material are released and may cause osteolysis, aseptic loosening, inflammation at the implant interface, among other problems, leading to the need for surgical revision [66].

The debris generated by wear decreases the lifespan of the implant. Thus, extensive research has been done to improve UHMWPE's wear resistance and, consequently, its clinical performance. The Hymaler, a UHMWPE with high crystallinity (73.12\%), emerged in 1980 as an alternative to the conventional UHMWPE. This material has a high resistance to fatigue and creep propagation. However, it is susceptible to degradation related to oxidation, which affects its clinical performance. This material was replaced in 1997 by Marathon, a UHMWPE with crosslinks [57].

Therefore, crosslinks were created in the polymer matrix by subjecting UHMWPE to high irradiation doses (usually $\gamma$ or electron beam) to increase the UHMWPE wear resistance. The ionizing radiation creates free radicals through the cleavage of the $\mathrm{C}-\mathrm{H}$ and $\mathrm{C}-\mathrm{C}$ bonds of the polyethylene chain. The free radicals recombine and form crosslinks in the amorphous phase, which increases the hardness of the material and, consequently, its resistance to wear. However, some free radicals may not recombine, increasing the sensitivity of the material to oxidation. Additional treatments are necessary for the neutralization of these free radicals avoiding the weakening of the implant. 
After irradiation, such as remelting and annealing, thermal processes have been proposed to eliminate residual free radicals or recombine the free radicals and consequently improve the oxidation resistance. However, additional remelting treatment may reduce UHMWPE crystallinity and its mechanical properties [67]. The crosslinked UHMWPE thermally treated was clinically introduced in the United States for total arthroplasties from 1998 to reduce the implants' wear and surgical revision incidence resulting from osteolysis [68].

A strategy to reduce oxidative degradation is to apply antioxidants to the polymer. Vitamin $\mathrm{E}$ is a viable option and has the advantage of being a natural antioxidant. In 2007, ASTM published a standard specification for the UHMWPE medical grade mixed with vitamin E. In the same year, hip implants using vitamin E-impregnated reticulate UHMWPE were introduced in the United States, followed by knee implants in 2008 [69]. Besides preventing oxidative degradation, the addition of vitamin E to the crosslinked UHMWPE improves its wear resistance and maintains the mechanical properties of the material [66]. Although vitamin E effectively eliminates free radicals, it can reduce crosslinking degrees [70]. However, some studies have shown that this reduction can be mitigated by increasing irradiation temperature or performing annealing after irradiation [67]. Studies have already proven that the wear of crosslinked UHMWPE and the crosslinked UHMWPE-antioxidant (impregnated with vitamin E) have been improved compared to the use of conventional UHMWPE [71,72]. The crosslinked UHMWPE and the crosslinked UHMWPE in the presence of antioxidants are used in most hip arthroplasty procedures in the United States [73].

\section{UHMWPE/HA Composites for Biomedical Application}

Ideal bone repair materials should be similar to human bone tissue: they should induce bone cells to infiltrate the implanted material and have good mechanical properties around bone tissue [74].

Due to the increasing demand for more efficient bone substitutes, UHMWPE/HA composites, and nanocomposites emerge as alternatives to materials already used in orthopedic prostheses. UHMWPE provides good mechanical properties in this material, and HA provides greater integration between the bone tissue and the implant.

\subsection{Hydroxyapatite}

Bone can be considered a natural nanocomposite consisting of collagen fiber networks impregnated with calcium phosphates, mainly HA nanocrystals. HA is a biocompatible material and is the main constituent of the mineral phase of bone. It is a mineral of the family of apatites with a hexagonal crystalline structure, with a molecular formula $\mathrm{Ca}_{10}\left(\mathrm{PO}_{4}\right)_{6}(\mathrm{OH})_{2}$ and with a molar ratio $\mathrm{Ca} / \mathrm{P}$ of 1.667 [75].

HA has poor mechanical properties such as low fatigue resistance, high fragility, low mechanical strength, and low fracture toughness. However, HA is an osteoconductive material, allowing bone growth, establishing chemical bonds with bone tissue without causing any local or systemic toxicity, inflammation, or response to a foreign body. Several studies have been developed to overcome the lack of superior mechanical properties applying synthetic HA and more strength materials aiming its application in bone repair [76]. When a material containing HA is implanted, a layer containing carbonated apatite is formed on its surface, contributing to the implant's bonding with the living tissue, resulting in a faster stabilization and superior fixation of the implant neighboring tissues [25].

\subsection{UHMWPE/HA Properties}

UHMWPE has a high molar weight $\left(3-8 \times 10^{6} \mathrm{~g} / \mathrm{mol}\right)$, providing excellent properties, as already mentioned. However, its high molar weight generates an increase in chain entanglements, reducing its mobility. The high molar weight provides high viscosity to the molten material that the polymer does not flow during its processing. UHMWPE's high viscosity hinders its processing, and the dispersion of the fillers in this matrix is inhibited. Due to the difficulties mentioned, some studies investigate ways 
to facilitate UHMWPE processing since the conventional injection and extrusion processes cannot be applied.

Some methods for processing UHMWPE/HA composites are reported in the literature, such as twin-screw extrusion, compression molding, and the use of a ball mill. It is worth mentioning that the compounds' properties will reflect the homogeneous dispersion of HA particles in UHMWPE provided by each method.

The ball mill is an alternative to produce composites where melting or dissolving the matrix is hindered, allowing the mixing of components in the solid phase [16]. Maksimkin et al. [77] mixed UHMWPE and micro-sized HA particles using a planetary ball mill, and then the material was hot pressed. First, a study of the UHMWPE structure was carried out by differential scanning calorimetry since the polymer chain's length influences the material's melting point. It was confirmed that the method of mechanical activation in solid phase did not change the structure of the UHMWPE because the melting point of the mechanically treated UHMWPE and the initial UHMWPE were the same. It was also verified that the increase in the amount of HA increased the degree of crystallinity compared to the pure polymer. Consequently, it generated an increase in the elastic modulus of the composite and by adding $50 \mathrm{wt} . \%$ of HA lower wear and friction coefficient were obtained.

In a similar process, Liu et al. [78] used micro-sized HA particles obtained from bovine bone (BHA) to prepare a UHMWPE/BHA composite. UHMWPE and BHA were mixed in a ball mill in the presence of ethanol and, after $8 \mathrm{~h}$ of mixing, the ethanol was evaporated, and then the mixture was hot pressed. It was observed that the elastic modulus and hardness increased progressively with the increase of BHA content up to a maximum, which was around 20-30 wt.\%. Then, a decrease of these properties was observed, justified by an inefficient dispersion of BHA particles. The addition of BHA also decreased the friction coefficient by up to $35 \%$ compared to the pure polymer. It was also performed the wear test in human plasma, and a decrease in the wear rate was observed for the composites. A $40 \%$ reduction in the wear rate was obtained when $20 \mathrm{wt} . \%$ of BHA was added. Wang et al. [79] prepared UHMWPE/BHA composites similar to those mentioned above [78]. They studied the wear of these composites against the femoral head of hip prostheses made of $\mathrm{Co}-\mathrm{Cr}$-Mo alloy in a joint simulator. The researchers observed that when the BHA content is less than $30 \mathrm{wt} . \%$, the wear rate decreased considerably, while in larger amounts, the reduction in the wear rate was lower, about $3 \%$. It was also investigated the relation of BHA content with the size of particles generated by wear. It was observed that the addition above $20 \mathrm{wt} . \%$ of BHA increased the size of these particles. It is positive from a clinical perspective since macrophages phagocytose particles were smaller than $1 \mu \mathrm{m}$ while only surrounding larger particles [79].

One treatment that can be performed to increase the mobility of the UHMWPE chains is swelling. Examples of swelling with paraffin oil, a non-toxic compound of the same chemical composition as UHMWPE, are reported in the literature [14,80-82]. Swelling increases the distance between UHMWPE chains, reduces the system's viscosity, and facilitates the incorporation of HA particles. However, paraffin oil must be removed from the medium not to affect the composite's mechanical properties. However, its removal involves long steps, including extraction with hexane or acetone.

Fang et al. [80] studied the effect of paraffin oil swelling on UHMWPE/nano-HA nanocomposites preparation. First, nano-HA particles were milled in a ball mill in the presence of ethanol, then UHMWPE was added to the mill, followed by paraffin oil. The oil was extracted, and the mixture was hot pressed. During the composite preparation, it was observed that the milling of HA particles provided the reduction of its particles to nanometric scales, allowing its uniform dispersion in the UHMWPE matrix. The HA that was not milled had difficulty penetrating between the polymer chains. It was also observed that the treatment with milling and swelling had significantly improved the stiffness of the composite, increasing its modulus by approximately $85 \%$ concerning the pure polymer.

In another study that used paraffin oil to increase UHMWPE mobility, Mirsalehi et al. [81] previously treated UHMWPE with paraffin oil at high temperatures. Following the swelling, UHMWPE was transferred to a mixing chamber, and after melting, the nano-HA particles were added. Subsequently to 
the mixture, the paraffin oil was extracted, and the material was hot pressed. Mechanical and tribological tests were performed. The increase in nano-HA content provided an increase in the elastic modulus, and hardness was observed compared to the pure polymer. It also provided a reduction in the coefficient of friction. The addition of $50 \mathrm{wt} . \%$ of nano-HA increased the composite elastic modulus by $362.5 \%$ and its hardness by $200 \%$, whereas the coefficient of friction was $38.86 \%$ lower than that of the pure UHMWPE. Later, in another study, Mirsalehi et al. [14] performed an in vitro study of these nanocomposites. They verified that nano-HA presence in the composite accelerated the proliferation of osteoblastic cells and stimulated osteoblasts' activity in forming a new bone structure within and on the nanocomposite surface. All the synthesized composites were shown to be biocompatible and non-toxic, and these characteristics improved with the increase of the nano-HA content.

Fang et al. [82] used a twin-screw extruder to prepare UHMWPE/nano-HA nanocomposites combined with the swelling process. UHMWPE and nano-HA were mixed with paraffin oil, and then the mixture was extruded twice. First, with a rotation speed of $5 \mathrm{rpm}$ and then $30 \mathrm{rpm}$. The oil was extracted, and the granules were molded by compression. It was observed that the composites elastic modulus progressively increased with the increase in the amount of nano-HA. The elastic modulus of the composite with $50 \mathrm{vol} \%$ of nano-HA reached about nine times the elastic modulus of pure UHMWPE. In a later study, the same authors studied the composite's biocompatibility with 0.5 vol\% of nano-HA prepared as previously described, adding a hot drawing step at the end of the process. This additional step led to an orientation of the UHMWPE chains, which justifies the increase in almost $100 \%$ of the composite elastic modulus. The bioactivity study showed that the composite has an excellent ability to induce calcium phosphate formation on its surface in the presence of simulated body fluid, creating a favorable environment for bone tissue growth [83].

In another study, UHMWPE bioactive composites were prepared by a twin-screw extruder without a swelling treatment [84]. The HA structure allows the replacement of the $\mathrm{PO}_{4}{ }^{3-}$ and $\mathrm{OH}^{-}$groups by $\mathrm{CO}_{3}{ }^{2-}$, producing carbonated hydroxyapatite (CHA). It is reported that the natural bone contains 2.8-14.7 wt.\% of carbonate in its composition [85,86]. Therefore, the UHMWPE/CHA composites were prepared. The composites' elastic modulus increased with the increase of CHA content, while for higher CHA contents, the tensile strength decreased due to the filler agglomeration. The bioactive in vitro assay showed that the composites produced are bioactive, inducing apatite precipitation. However, the precipitation of apatite, on the material's surface, in the composite with 5 wt. $\%$ of $\mathrm{CHA}$ was not homogeneous. Higher filler content can promote agglomeration of the particles in the polymeric matrix, and fewer bioactive sites will be available to induce apatite precipitation.

Another UHMWPE/HA preparation technique is compression molding. Crowley and Chalivendra [87] prepared UHMWPE nanocomposites with nano-HA, primary mixing the components mechanically and then molding them by compression. The results obtained for the nanocomposites were compared with the UHMWPE currently employed in joint implants. Transmission electron microscopy showed that the increase in nanofiller's amount increased the agglomeration of nano-HA particles in the polymer matrix, and the agglomeration was intense above $5 \mathrm{vol} \%$. The addition of nano-HA reduced the elongation at break, while the elastic modulus increased with the nanofiller content. It was observed that the maximum increase in the elastic modulus was only $9 \%$ concerning the pure polymer when $3 \mathrm{vol} \%$ of nano-HA was added.

Panin et al. [88] prepared composites and nanocomposites by compression molding and studied the wear resistance of these materials. They also prepared other composites and nanocomposites, which were irradiated by a nitrogen ion beam. It was observed that the wear rate decreased for both composites and nanocomposites when compared with the pure polymer. The addition of only 0.1-0.5 wt.\% of nano-HA to UHMWPE increased its wear resistance by 3.5 times compared to pure polymer, while adding $40 \mathrm{wt} \%$ of HA provided similar wear resistance. On the other hand, the nano and micro composites with a treated surface with nitrogen increased the wear resistance by around 10-30\%. Another factor observed was that irradiation increased the crystallinity of the pure polymer, the composites, and the nanocomposites. 
In another study, Li et al. [89] prepared UHMWPE/nano-HA nanocomposites by compression molding and examined their mechanical properties. The performed tests showed that the nanocomposites' elastic modulus, once again, increased almost linearly with the addition of nano-HA. The maximum increase was $34 \%$ compared to the pure polymer and was obtained by adding $20 \%$ of nano-HA to the polymer matrix. On the other hand, the tensile strength decreased, and the creep resistance increased with nano-HA presence.

\section{Final Considerations}

Synthetic polymers have been used since the 1980s as implantable materials and stand out for their controllable biomechanical properties [90,91]. However, their lack of adhesion with the living bone tissue is still an issue that must be overcome. Thus, the application of synthetic polymers in bone replacement requires modifications in their properties. As evidenced in this review, UHMWPE has excellent mechanical properties, which make its application as a bone substitute extremely attractive. UHMWPE is a non-toxic and biocompatible material, authorized by the FDA to be in direct contact with food and medicines and implanted in the human body, but it fails in bioactivity. The inclusion of bioactive nanofillers into the polymer matrix creates a structure that closely mimics the natural bone characteristics. Nonetheless, UHMWPE/HA composites still have drawbacks associated with the formation of wear particles and the material's fatigue resistance. For this reason, this material has been widely studied [92-97].

The major challenge in produce prosthetic devices lies in polymer processing techniques. Throughout the centuries, the materials used in prostheses as well as the techniques used to manufacture them have been changed. The latest advanced technique that has gained strength in the last decades is 3D printing, producing exciting results $[98,99]$. 3D printing is already applied in the clinical field, producing customized implants for bone replacement [100,101]. Future outlooks in prosthesis development will drive improved materials and manufacturing techniques, leading to increased implant lifespan.

Author Contributions: Conceptualization; writing—original draft preparation; writing—review and editing, M.R.S., and M.d.F.V.M. All authors have read and agreed to the published version of the manuscript.

Funding: This research was funded by CAPES, CNPQ, and FAPERJ.

Conflicts of Interest: The authors declare no conflict of interest.

\section{References}

1. Haach, L.C.A.; Purqueiro, B.M.; Silva Júnior, N.F.; Gaspar, A.M.M.; Fortulan, C.A. Comparison of Two Composites Developed to be Used as Bone Replacement-PMMA/Bioglass $4555^{\circledR}$ Microfiber and PMMA/Hydroxyapatite. Bioceram. Dev. Appl. 2014, 4, 1-3. [CrossRef]

2. Oryan, A.; Alidadi, S.; Moshiri, A.; Maffulli, N. Bone regenerative medicine: Classic options, novel strategies, and future directions. J. Orthop. Surg. Res. 2014, 9, 1-27. [CrossRef] [PubMed]

3. Bobbert, F.S.L.; Zadpoor, A.A. Effects of bone substitute architecture and surface properties on cell response, angiogenesis, and structure of new bone. J. Mater. Chem. B 2017, 5, 6175-6192. [CrossRef] [PubMed]

4. Williams, A.; Szabo, R.M. Bone transplantation. Orthopedics 2004, 27, 488-495. [CrossRef] [PubMed]

5. Pinto, J.G.S. Enxerto autógeno $x$ biomateriais no tratamento de fraturas e deformidades faciais-uma revisão de conceitos atuais. Rev. Fac. Odontol.-UPF 2010, 12, 79-84. [CrossRef]

6. Amini, A.R.; Laurencin, C.T.; Nukavarapu, S.P. Bone tissue engineering: Recent advances and challenges. Crit. Rev. Biomed. Eng. 2012, 40, 363-408. [CrossRef]

7. Delloye, C.; Cornu, O.; Druez, V.; Barbier, O. Bone allografts: What they can offer and what they cannot. J. Bone Jt. Surg. 2007, 89-B, 574-580. [CrossRef]

8. Bus, M.; Dijkstra, P.; van de Sande, M.A.J.; Taminiau, A.H.M.; Schreuder, H.W.B.; Jutte, P.C.; van der Geest, I.C.M.; Schaap, G.R.; Bramer, J.A.M. Intercalary Allograft Reconstructions Following Resection of Primary Bone Tumors. JBJS 2014, 96, 1-11. [CrossRef] 
9. Sheikh, Z.; Sima, C.; Glogauer, M. Bone replacement materials and techniques used for achieving vertical alveolar bone augmentation. Materials 2015, 8, 2953-2993. [CrossRef]

10. Bose, S.; Banerjee, D.; Bandyopadhyay, A. Introduction to Biomaterials and Devices for Bone Disorders. In Materials and Devices for Bone Disorders; Elsevier Inc.: Amsterdam, The Netherlands, 2017; pp. 1-27. ISBN 9780128027929.

11. Pryor, L.S.; Gage, E.; Langevin, C.-J.; Herrera, F.; Breithaupt, A.D.; Gordon, C.R.; Afifi, A.M.; Zins, J.E.; Meltzer, H.; Gosman, A.; et al. Review of bone substitutes. Craniomaxillofac. Trauma Reconstr. 2009, 2, 151-160. [CrossRef]

12. Saini, M. Implant biomaterials: A comprehensive review. World J. Clin. Cases 2015, 3, 52-57. [CrossRef] [PubMed]

13. Sattari, M.; Naimi-Jamal, M.R.; Khavandi, A. Interphase evaluation and nano-mechanical responses of UHMWPE/SCF/nano- SiO2 hybrid composites. Polym. Test. 2014, 38, 26-34. [CrossRef]

14. Mirsalehi, S.A.; Sattari, M.; Khavandi, A.; Mirdamadi, S.; Naimi-Jamal, M.R. Tensile and biocompatibility properties of synthesized nano-hydroxyapatite reinforced ultrahigh molecular weight polyethylene nanocomposite. J. Compos. Mater. 2016, 50, 1725-1737. [CrossRef]

15. Aparecida, A.H.; Fook, M.V.L.; Guastaldi, A.C. Biomimetic apatite formation on Ultra-High Molecular Weight Polyethylene (UHMWPE) using modified biomimetic solution. J. Mater. Sci. Mater. Med. 2009, 20, 1215-1222. [CrossRef] [PubMed]

16. Macuvele, D.L.P.; Nones, J.; Matsinhe, J.V.; Lima, M.M.; Soares, C.; Fiori, M.A.; Riella, H.G. Advances in ultra high molecular weight polyethylene/hydroxyapatite composites for biomedical applications: A brief review. Mater. Sci. Eng. C 2017, 76, 1248-1262. [CrossRef] [PubMed]

17. Porter, J.R.; Ruckh, T.T.; Popat, K.C. Bone tissue engineering: A review in bone biomimetics and drug delivery strategies. Biotechnol. Prog. 2009, 25, 1539-1560. [CrossRef]

18. Boyle, W.J.; Simonet, W.S.; Lacey, D.L. Osteoclast differentiation and activation and Activation. Nature 2003, 423, 337-342. [CrossRef]

19. Boskey, A.L. Bone composition: Relationship to bone fragility and antiosteoporotic drug effects. Bonekey Rep. 2013, 2, 447. [CrossRef]

20. Sommerfeldt, D.; Rubin, C. Biology of bone and how it orchestrates the form and function of the skeleton. Eur. Spine J. 2001, 10, 86-95. [CrossRef]

21. Jiang, W.; Liu, H. Nanocomposites for bone repair and osteointegration with soft tissues. In Nanocomposites for Musculoskeletal Tissue Regeneration; Liu, H., Ed.; Woodhead Publishing: Cambridge, UK, 2016; pp. $241-257$. ISBN 9781782424758.

22. Seeman, E.M.D.; Delmas, P.D. Bone Quality-The Material and Structural Basis of Bone Strength and Fragility. N. Engl. J. Med. 2006, 354, 2250-2261. [CrossRef]

23. Rizzo, D.C. Fundamentals of Anatomy and Physiology, 3rd ed.; Delmar Cengage Learning: New York, NY, USA, 2010; ISBN 9781435438712.

24. Michael, F.M.; Khalid, M.; Walvekar, R.; Ratnam, C.T.; Ramarad, S.; Siddiqui, H.; Hoque, M.E. Effect of nanofillers on the physico-mechanical properties of load bearing bone implants. Mater. Sci. Eng. C 2016, 67, 792-806. [CrossRef] [PubMed]

25. Sadat-Shojai, M.; Khorasani, M.T.; Dinpanah-Khoshdargi, E.; Jamshidi, A. Synthesis methods for nanosized hydroxyapatite with diverse structures. Acta Biomater. 2013, 9, 7591-7621. [CrossRef] [PubMed]

26. Salgado, A.J.; Coutinho, O.P.; Reis, R.L. Bone tissue engineering: State of the art and future trends. Macromol. Biosci. 2004, 4, 743-765. [CrossRef] [PubMed]

27. Bozic, K.J. Sixth Annual AJRR Annual Report on Hip and Knee Arthroplasty Data. Am. Jt. Replace. Regist. 2019. Available online: https://connect.ajrr.net/hubfs/PDFs\%20and\%20PPTs/AAOS_AJRR_2019_Annual_ Report_Update_FINAL_150DPI.pdf?hsCtaTracking=1d80e9fa-66fe-4525-a5cb-15c30ec19a1f\%7C8becda93a51e-41cc-bcfa-ca9130c1add6 (accessed on 1 November 2020).

28. Kurtz, S.; Ong, K.; Lau, E.; Mowat, F.; Halpern, M. Projections of primary and revision hip and knee arthroplasty in the United States from 2005 to 2030. J. Bone Jt. Surg. Am. Vol. 2007, 89A, 780-785. [CrossRef]

29. Dang, T.T.; Nikkhah, M.; Memic, A.; Khademhosseini, A. Polymeric Biomaterials for Implantable Prostheses; Elsevier Inc.: Amsterdam, The Netherlands, 2014; ISBN 9780123969835.

30. Gohil, S.V.; Suhail, S.; Rose, J.; Vella, T.; Nair, L.S. Polymers and Composites for Orthopedic Applications; Elsevier Inc.: Amsterdam, The Netherlands, 2017; ISBN 978-0-12-802792-9. 
31. Navarro, M.; Michiardi, A.; Castaño, O.; Planell, J.A. Biomaterials in orthopaedics. J. R. Soc. Interface 2008, 5 , 1137-1158. [CrossRef]

32. Arora, M.; Chan, E.K.; Gupta, S.; Diwan, A.D. Polymethylmethacrylate bone cements and additives: A review of the literature. World J. Orthop. 2013, 4, 67-74. [CrossRef]

33. Chen, L.; Zhai, D.; Huan, Z.; Ma, N.; Zhu, H.; Wu, C.; Chang, J. Silicate bioceramic/PMMA composite bone cement with distinctive physicochemical and bioactive properties. RSC Adv. 2015, 5, 37314-37322. [CrossRef]

34. Nussbaum, D.A.; Gailloud, P.; Murphy, K. The Chemistry of Acrylic Bone Cements and Implications for Clinical Use in Image-guided Therapy. J. Vasc. Interv. Radiol. 2004, 15, 121-126. [CrossRef]

35. Sa, Y.; Yang, F.; De Wijn, J.R.; Wang, Y.; Wolke, J.G.C.; Jansen, J.A. Physicochemical properties and mineralization assessment of porous polymethylmethacrylate cement loaded with hydroxyapatite in simulated body fluid. Mater. Sci. Eng. C 2016, 61, 190-198. [CrossRef]

36. Goñi, I.; Rodríguez, R.; García-Arnáez, I.; Parra, J.; Gurruchaga, M. Preparation and characterization of injectable PMMA-strontium-substituted bioactive glass bone cement composites. J. Biomed. Mater. Res. Part B Appl. Biomater. 2017, 1-13. [CrossRef] [PubMed]

37. D'Onofrio, A.; Kent, N.W.; Shahdad, S.A.; Hill, R.G. Development of novel strontium containing bioactive glass based calcium phosphate cement. Dent. Mater. 2016, 32, 703-712. [CrossRef] [PubMed]

38. Cui, X.; Huang, C.; Zhang, M.; Ruan, C.; Peng, S.; Li, L.; Liu, W.; Wang, T.; Li, B.; Huang, W.; et al. Enhanced osteointegration of poly (methylmethacrylate) bone cements by incorporating strontium-containing borate bioactive glass. J. R. Soc. Interface 2017, 14, 20161057. [CrossRef] [PubMed]

39. Kurtz, S.M. Synthesis and Processing of PEEK for Surgical Implants; Elsevier Inc.: Amsterdam, The Netherlands, 2012; ISBN 9781437744637.

40. Kemmish, D.J.; Wilson, B. Aromatic Polyetherketones. U.S. Patent 6,909,015 B2, 21 June 2005.

41. Lu, T.; Qian, S.; Meng, F.; Ning, C.; Liu, X. Enhanced osteogenic activity of poly ether ether ketone using calcium plasma immersion ion implantation. Colloids Surf. B Biointerfaces 2016, 142, 192-198. [CrossRef] [PubMed]

42. Johansson, P.; Jimbo, R.; Naito, Y.; Kjellin, P.; Currie, F.; Wennerberg, A. Polyether ether ketone implants achieve increased bone fusion when coated with nano-sized hydroxyapatite: A histomorphometric study in rabbit bone. Int. J. Nanomed. 2016, 11, 1435-1442. [CrossRef]

43. Ma, R.; Guo, D. Evaluating the bioactivity of a hydroxyapatite-incorporated polyetheretherketone biocomposite. J. Orthop. Surg. Res. 2019, 14,1-13. [CrossRef]

44. Monich, P.R.; Berti, F.V.; Porto, L.M.; Henriques, B.; Novaes de Oliveira, A.P.; Fredel, M.C.; Souza, J.C.M. Physicochemical and biological assessment of PEEK composites embedding natural amorphous silica fibers for biomedical applications. Mater. Sci. Eng. C 2017, 79, 354-362. [CrossRef]

45. Khoury, J.; Selezneva, I.; Pestov, S.; Tarassov, V.; Ermakov, A.; Mikheev, A.; Lazov, M.; Kirkpatrick, S.R.; Shashkov, D.; Smolkov, A. Surface bioactivation of PEEK by neutral atom beam technology. Bioact. Mater. 2019, 4, 132-141. [CrossRef]

46. Terpiłowski, K.; Wiącek, A.E.; Jurak, M. Influence of nitrogen plasma treatment on the wettability of polyetheretherketone and deposited chitosan layers. Adv. Polym. Technol. 2018, 37, 1557-1569. [CrossRef]

47. Zhang, J.; Wei, W.; Yang, L.; Pan, Y.; Wang, X.; Wang, T.; Tang, S.; Yao, Y.; Hong, H.; Wei, J. Stimulation of cell responses and bone ingrowth into macro-microporous implants of nano-bioglass/polyetheretherketone composite and enhanced antibacterial activity by release of hinokitiol. Colloids Surf. B Biointerfaces 2018, 164, 347-357. [CrossRef]

48. Zheng, Y.; Liu, L.; Xiao, L.; Zhang, Q.; Liu, Y. Enhanced osteogenic activity of phosphorylated polyetheretherketone via surface-initiated grafting polymerization of vinylphosphonic acid. Colloids Surf. B Biointerfaces 2019, 173, 591-598. [CrossRef] [PubMed]

49. Zheng, Y.; Liu, L.; Ma, Y.; Xiao, L.; Liu, Y. Enhanced Osteoblasts Responses to Surface-Sulfonated Polyetheretherketone via a Single-Step Ultraviolet-Initiated Graft Polymerization. Ind. Eng. Chem. Res. 2018, 57, 10403-10410. [CrossRef]

50. Ma, R.; Tang, T. Current strategies to improve the bioactivity of PEEK. Int. J. Mol. Sci. 2014, 15, 5426-5445. [CrossRef] [PubMed]

51. Kasemo, B. Biological surface science Bengt. Surf. Sci. 2002, 500, 656-677. [CrossRef] 
52. Almasi, D.; Iqbal, N.; Sadeghi, M.; Sudin, I.; Abdul Kadir, M.R.; Kamarul, T. Preparation Methods for Improving PEEK's Bioactivity for Orthopedic and Dental Application: A Review. Int. J. Biomater. 2016, 2016. [CrossRef] [PubMed]

53. Poulsson, A.H.C.; Richards, R.G. Surface Modification Techniques of Polyetheretherketone, Including Plasma Surface Treatment; Elsevier Inc.: Amsterdam, The Netherlands, 2012; ISBN 9781437744637.

54. Wang, H.; Lu, T.; Meng, F.; Zhu, H.; Liu, X. Enhanced osteoblast responses to poly ether ether ketone surface modified by water plasma immersion ion implantation. Colloids Surf. B Biointerfaces 2014, 117, 89-97. [CrossRef]

55. Kurtz, S.M.; Devine, J.N. PEEK biomaterials in trauma, orthopedic, and spinal implants. Biomaterials 2007, 28, 4845-4869. [CrossRef]

56. Ma, R.; Tang, S.; Tan, H.; Lin, W.; Wang, Y.; Wei, J.; Zhao, L.; Tang, T. Preparation, characterization, and in vitro osteoblast functions of a nano-hydroxyapatite/polyetheretherketone biocomposite as orthopedic implant material. Int. J. Nanomed. 2014, 9, 3949-3961. [CrossRef]

57. Kurtz, S.M. UHMWPE Biomaterials Handbook: Ultra-High Molecular Weight Polyethylene in Total Joint Replacement and Medical Devices; William Andrew: Oxford, UK, 2015; ISBN 9780323354011.

58. Roeder, R.K.; Converse, G.L.; Kane, R.J.; Yue, W. Hydroxyapatite-reinforced polymer biocomposites for synthetic bone substitutes. J. Miner. Met. Mater. Soc. 2008, 60, 38-45. [CrossRef]

59. Wagoner Johnson, A.J.; Herschler, B.A. A review of the mechanical behavior of $\mathrm{CaP}$ and $\mathrm{CaP} /$ polymer composites for applications in bone replacement and repair. Acta Biomater. 2011, 7, 16-30. [CrossRef]

60. Aherwar, A.; KSingh, A.K.; Patnaik, A. Current and future biocompatibility aspects of biomaterials for hip prosthesis. AIMS Bioeng. 2016, 3, 23-43. [CrossRef]

61. Zhao, Y.; Li, H.; Zhang, Z.; Celli, J.; Percec, S.; Ren, F. Nanoindentation study of time-dependent mechanical properties of ultra-high-molecular-weight polyethylene (UHMWPE) at different temperatures. Polym. Test. 2020, 91, 106787. [CrossRef]

62. Muhsin, S.A.; Hatton, P.V.; Johnson, A.; Sereno, N.; Wood, D.J. Determination of Polyetheretherketone (PEEK) mechanical properties as a denture material. Saudi Dent. J. 2019, 31, 382-391. [CrossRef]

63. Wypych, G. Handbook of Polymers, 2nd ed.; ChemTec Publishing: Toronto, ON, USA, 2016; ISBN 9781895198928.

64. Kajima, Y.; Takaichi, A.; Kittikundecha, N.; Nakamoto, T.; Kimura, T.; Nomura, N.; Kawasaki, A.; Hanawa, T.; Takahashi, H.; Wakabayashi, N. Effect of heat-treatment temperature on microstructures and mechanical properties of Co-Cr-Mo alloys fabricated by selective laser melting. Mater. Sci. Eng. A 2018, 726, 21-31. [CrossRef]

65. Ao, N.; Liu, D.; Liu, C.; Zhang, X.; Liu, D. Face-centered titanium induced by ultrasonic surface rolling process in Ti-6Al-4V alloy and its tensile behavior. Mater. Charact. 2018, 145, 527-533. [CrossRef]

66. Massin, P.; Achour, S. Wear products of total hip arthroplasty: The case of polyethylene. Morphologie 2016, 101, 1-8. [CrossRef] [PubMed]

67. Yamamoto, K.; Tateiwa, T.; Takahashi, Y. Vitamin E-stabilized highly crosslinked polyethylenes: The role and effectiveness in total hip arthroplasty. J. Orthop. Sci. 2017, 22, 384-390. [CrossRef]

68. Kurtz, S.M.; Gawel, H.A.; Patel, J.D. History and systematic review of wear and osteolysis outcomes for first-generation highly crosslinked polyethylene. Clin. Orthop. Relat. Res. 2011, 469, 2262-2277. [CrossRef]

69. Bracco, P.; Oral, E. Vitamin E-stabilized UHMWPE for total joint implants: A review. Clin. Orthop. Relat. Res. 2011, 469, 2286-2293. [CrossRef]

70. Yousef, S.; Visco, A.; Galtieri, G.; Nocita, D.; Espro, C. Wear behaviour of UHMWPE reinforced by carbon nanofiller and paraffin oil for joint replacement. Mater. Sci. Eng. C 2017, 73, 234-244. [CrossRef]

71. Affatato, S.; Freccero, N.; Taddei, P. The biomaterials challenge: A comparison of polyethylene wear using a hip joint simulator. J. Mech. Behav. Biomed. Mater. 2016, 53, 40-48. [CrossRef] [PubMed]

72. Chen, G.; Ni, Z.; Qian, S.; Zhao, Y. Biotribological behaviour of Vitamin E-blended highly cross-linked UHMWPE in a hip joint simulator. Ind. Lubr. Tribol. 2016, 68, 548-553. [CrossRef]

73. Bozic, K. Fifth Ajrr Annual Report on Hip and Knee Arthroplasty Data; American Joint Replacement Registry: Rosemont, IL, USA, 2018.

74. Quan, C.; Tang, Y.; Liu, Z.; Rao, M.; Zhang, W.; Liang, P.; Wu, N.; Zhang, C.; Shen, H.; Jiang, Q. Effect of modification degree of nanohydroxyapatite on biocompatibility and mechanical property of injectable poly(methyl methacrylate)-based bone cement. J. Biomed. Mater. Res.-Part B Appl. Biomater. 2016, 104, 576-584. [CrossRef] [PubMed] 
75. Best, S.M.; Porter, A.E.; Thian, E.S.; Huang, J. Bioceramics: Past, present and for the future. J. Eur. Ceram. Soc. 2008, 28, 1319-1327. [CrossRef]

76. Prakasam, M.; Locs, J.; Salma-Ancane, K.; Loca, D.; Largeteau, A.; Berzina-Cimdina, L. Fabrication, Properties and Applications of Dense Hydroxyapatite: A Review. J. Funct. Biomater. 2015, 6, 1099-1140. [CrossRef]

77. Maksimkin, A.V.; Kaloshkin, S.D.; Tcherdyntsev, V.V.; Senatov, F.S.; Danilov, V.D. Structure and properties of ultra-high molecular weight polyethylene filled with disperse hydroxyapatite. Inorg. Mater. Appl. Res. 2012, 3, 288-295. [CrossRef]

78. Liu, J.; Zhu, Y.; Wang, Q.; Ge, S. Biotribological behavior of ultra high molecular weight polyethylene composites containing bovine bone hydroxyapatite. J. China Univ. Min. Technol. 2008, 18, 606-612. [CrossRef]

79. Wang, Q.; Liu, J.; Ge, S. Study on Biotribological Behavior of the Combined Joint of CoCrMo and UHMWPE/BHA Composite in a Hip Joint Simulator. J. Bionic Eng. 2009, 6, 378-386. [CrossRef]

80. Fang, L.; Leng, Y.; Gao, P. Processing of hydroxyapatite reinforced ultrahigh molecular weight polyethylene for biomedical applications. Biomaterials 2005, 26, 3471-3478. [CrossRef]

81. Mirsalehi, S.A.; Khavandi, A.; Mirdamadi, S.; Naimi-Jamal, M.R.; Kalantari, S.M. Nanomechanical and tribological behavior of hydroxyapatite reinforced ultrahigh molecular weight polyethylene nanocomposites for biomedical applications. J. Appl. Polym. Sci. 2015, 132, 1-11. [CrossRef]

82. Fang, L.; Leng, Y.; Gao, P. Processing and mechanical properties of HA/UHMWPE nanocomposites. Biomaterials 2006, 27, 3701-3707. [CrossRef]

83. Fang, L.; Gao, P.; Leng, Y. High strength and bioactive hydroxyapatite nano-particles reinforced ultrahigh molecular weight polyethylene. Compos. Part B Eng. 2007, 38, 345-351. [CrossRef]

84. Senra, M.R.; Vieira Marques, M.d.F.; de Holanda Saboya Souza, D. Ultra-high molecular weight polyethylene bioactive composites with carbonated hydroxyapatite. J. Mech. Behav. Biomed. Mater. 2020, 110, 103938. [CrossRef]

85. Liao, S.; Watari, F.; Uo, M.; Ohkawa, S.; Tamura, K.; Wang, W.; Cui, F. The Preparation and Characteristics of a Carbonated Hydroxyapatite/Collagen Composite at Room Temperature. J. Biomed. Mater. Res.-Part B Appl. Biomater. 2005, 74, 817-821. [CrossRef]

86. Senra, M.R.; Lima, R.B.; Souza, D.d.H.S.; Marques, M.d.F.V.; Monteiro, S.N. Thermal characterization of hydroxyapatite or carbonated hydroxyapatite hybrid composites with distinguished collagens for bone graft. J. Mater. Res. Technol. 2020, 9, 7190-7200. [CrossRef]

87. Crowley,J.; Chalivendra, V.B. Mechanical characterization of ultra-high molecular weight polyethylene-hydroxyapatite nanocomposites. Biomed. Mater. Eng. 2008, 18, 149-160. [CrossRef]

88. Panin, S.V.; Kornienko, L.A.; Chaikina, M.V.; Sergeev, V.P.; Ivanova, L.R.; Shilko, S.V. Nano- and Micro-Structured UHMWPE Composites Filled With Hydroxyapatite Irradiated by Nitrogen Ion Beams for Bio-Medical Applications. Russ. Phys. J. 2014, 56, 1137-1143. [CrossRef]

89. Li, F.; Gao, L.; Gao, H.; Cui, Y. The Mechanical Properties and Modeling of Creep Behavior of UHMWPE/Nano-HA Composites. J. Mater. Eng. Perform. 2017, 26, 4514-4521. [CrossRef]

90. Hacker, M.C.; Krieghoff, J.; Mikos, A.G. Synthetic polymers. In Principles of Regenerative Medicine; Atala, A., Lanza, R., Mikos, A.G., Nerem, R., Eds.; Elsevier Inc.: Amsterdam, The Netherlands, 2019; pp. 559-590. ISBN 9780128098806.

91. Haugen, H.J.; Lyngstadaas, S.P.; Rossi, F.; Perale, G. Bone grafts: Which is the ideal biomaterial? J. Clin. Periodontol. 2019, 46, 92-102. [CrossRef]

92. Saravanan, I.; Devaraju, A. Wear mechanism of UHMWPE polymer composites for bio medical applications. Mater. Res. Express 2019, 6, 1-11. [CrossRef]

93. Salari, M.; Mohseni Taromsari, S.; Bagheri, R.; Faghihi Sani, M.A. Improved wear, mechanical, and biological behavior of UHMWPE-HAp-zirconia hybrid nanocomposites with a prospective application in total hip joint replacement. J. Mater. Sci. 2019, 54, 4259-4276. [CrossRef]

94. Macuvele, D.L.P.; Colla, G.; Cesca, K.; Ribeiro, L.F.B.; da Costa, C.E.; Nones, J.; Breitenbach, E.R.; Porto, L.M.; Soares, C.; Fiori, M.A.; et al. UHMWPE/HA biocomposite compatibilized by organophilic montmorillonite: An evaluation of the mechanical-tribological properties and its hemocompatibility and performance in simulated blood fluid. Mater. Sci. Eng. C 2019, 100, 411-423. [CrossRef] [PubMed] 
95. Liu, Z.; Wang, J.; Gao, H.; Gao, L. Biaxial fatigue crack propagation behavior of ultrahigh molecular weight polyethylene reinforced by carbon nanofibers and hydroxyapatite. J. Biomed. Mater. Res.-Part B Appl. Biomater. 2020, 108, 1603-1615. [CrossRef] [PubMed]

96. Shi, G.; Yan, X.; Wang, Q.; Cao, Z.; Min, L.; Ji, L. Hydroxyapatite/ultra-high molecular weight polyethylene nanocomposites fabricated by in situ hydrothermal synthesis for wear-resistance and friction reduction. J. Appl. Polym. Sci. 2020, 137, 1-14. [CrossRef]

97. Taromsari, S.M.; Salari, M.; Bagheri, R.; Sani, M.A.F. Optimizing tribological, tensile \& in-vitro biofunctional properties of UHMWPE based nanocomposites with simultaneous incorporation of graphene nanoplatelets (GNP) \& hydroxyapatite (HAp) via a facile approach for biomedical applications. Compos. Part B Eng. 2019, 175, 107181. [CrossRef]

98. Powell, S.K.; Cruz, R.L.J.; Ross, M.T.; Woodruff, M.A. Past, Present, and Future of Soft-Tissue Prosthetics: Advanced Polymers and Advanced Manufacturing. Adv. Mater. 2020, 32, 1-21. [CrossRef]

99. Ahangar, P.; Cooke, M.E.; Weber, M.H.; Rosenzweig, D.H. Current biomedical applications of 3D printing and additive manufacturing. Appl. Sci. 2019, 9, 1713. [CrossRef]

100. Winkler, T.; Sass, F.A.; Duda, G.N.; Schmidt-Bleek, K. A review of biomaterials in bone defect healing, remaining shortcomings and future opportunities for bone tissue engineering: The unsolved challenge. Bone Jt. Res. 2018, 7, 232-243. [CrossRef]

101. Ghilan, A.; Chiriac, A.P.; Nita, L.E.; Rusu, A.G.; Neamtu, I.; Chiriac, V.M. Trends in 3D Printing Processes for Biomedical Field: Opportunities and Challenges. J. Polym. Environ. 2020, 28, 1345-1367. [CrossRef]

Publisher's Note: MDPI stays neutral with regard to jurisdictional claims in published maps and institutional affiliations.

(C) 2020 by the authors. Licensee MDPI, Basel, Switzerland. This article is an open access article distributed under the terms and conditions of the Creative Commons Attribution (CC BY) license (http://creativecommons.org/licenses/by/4.0/). 